\title{
Axillary temperature measurement: a less stressful alternative for hospitalised cats?
}

1. M. Girod, DVM $\underline{1}$,

2. M. Vandenheede, DVM, PhD, Dip ECAWBM (WSEL) $\underline{1}$,

3. F. Farnir, PhD, Professor of Biostatistics 2 and

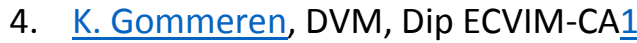

\pm Author Affiliations

1. ${ }^{1}$ Department of Small Animal Clinical Science, University of Liège, Quartier Vallée 2, Avenue de Cureghem, 3, B44, Liège 4000, Belgium

2. ${ }^{2}$ Department of Animal Production, University of Liège, Quartier Vallée 2, Avenue de Cureghem, 3, Liège 4000, Belgium

1. E-mail for correspondence: maudgirod@msn.com

\section{Abstract}

Rectal temperature measurement (RTM) can promote stress and defensive behaviour in hospitalised cats. The aim of this study was to assess if axillary temperature measurement (ATM) could be a reliable and less stressful alternative for these animals. In this prospective study, paired rectal and axillary temperatures were measured in 42 cats, either by a veterinarian or a student. To assess the impact of these procedures on the cat's stress state, their heart rate was checked and a cat stress score (CSS) was defined and graded from 1 (relaxed) to 5 (terrified). A moderate correlation was found between RTM and ATM ( $r=0.52 ; P<0.0001)$. RTM was on average $0.9^{\circ} \mathrm{C}\left(1.6^{\circ} \mathrm{F}\right)$ higher than ATM $(P<0.0001)$, although a wide variation was found in the difference between these two measurements $\left(-2.1^{\circ} \mathrm{C}\right.$ to $3.6^{\circ} \mathrm{C}\left(-3.8^{\circ} \mathrm{F}\right.$ to $\left.\left.6.5^{\circ} \mathrm{F}\right)\right)$. ATM failed to identify hypothermia in 25 per cent of the cases and hyperthermia in 19 per cent of the cases but may be considered less stressful than RTM. Indeed, RTM induced a mildly greater increase in heart rate $(+6 \mathrm{bpm} ; \mathrm{P}=0.01)$ and in CSS $(+0.2 ; \mathrm{P}=0.001)$ than ATM. The results were not affected by operator type. In conclusion, RTM should remain the standard method to obtain accurate temperatures in cats.

- Accepted January 8, 2016.

- Published Online First 1 February 2016 